\title{
Erratum to: Reliability and validity of the Dutch version of the Maternal Antenatal Attachment Scale
}

\section{Johan C. H. van Bussel • Bernard Spitz •}

Koen Demyttenaere

Published online: 30 January 2010

(C) Springer-Verlag 2010

Erratum to: Arch Womens Ment Health

DOI 10.1007/s00737-009-0127-9

Due to an unfortunate error the symbols in Table 4 have not been corrected. Therefore, the correct Table 4 is given here.

The online version of the original article can be found at http://dx.doi. org/10.1007/s00737-009-0127-9.

J. C. H. van Bussel $(\bowtie) \cdot K$. Demyttenaere Institute of Family and Sexuality Sciences,

Department of Public Health, Faculty of Medicine,

Katholieke Universiteit Leuven,

Kapucijnenvoer 33,

3000 Leuven, Belgium

e-mail: johan.vanbussel@med.kuleuven.be

B. Spitz

Department of Gynaecology and Obstetrics,

University Hospital Gasthuisberg,

Leuven, Belgium

K. Demyttenaere

Department of Neurosciences and Psychiatry,

University Hospital Gasthuisberg,

Leuven, Belgium 
Table 4 Correlations between maternal attachment during pregnancy (MAAS) and the independent study variables

\section{MAAS}

\begin{tabular}{|c|c|c|c|c|c|c|c|c|}
\hline \multicolumn{3}{|l|}{ Total } & \multicolumn{3}{|l|}{ Quality } & \multicolumn{3}{|c|}{ Preoccupation } \\
\hline $\mathrm{T} 1$ & $\mathrm{~T} 2$ & $\mathrm{~T} 3$ & $\mathrm{~T} 1$ & $\mathrm{~T} 2$ & $\mathrm{~T} 3$ & $\mathrm{~T} 1$ & $\mathrm{~T} 2$ & $\mathrm{~T} 3$ \\
\hline $0.15^{* *}$ & $0.15^{* *}$ & $0.19^{* *}$ & $0.14^{*}$ & $0.15^{* *}$ & $0.17^{* *}$ & $0.11^{\#}$ & $0.13^{*}$ & $0.17^{* *}$ \\
\hline $0.38^{* * *}$ & $0.37^{* * *}$ & $0.48^{* * *}$ & $0.29^{* * *}$ & $0.32^{* * *}$ & $0.40^{* * * *}$ & $0.36^{* * *}$ & $0.35^{* * *}$ & $0.40^{* * *}$ \\
\hline$-0.27^{* * *}$ & $-0.23^{* * *}$ & $-0.27^{* * *}$ & $-0.28^{* * *}$ & $-0.29^{* * *}$ & $-0.37^{* * *}$ & $-0.18^{* *}$ & $-0.13^{*}$ & $-0.12^{*}$ \\
\hline $0.22^{* * *}$ & $0.19^{* * *}$ & $0.18^{* * *}$ & $0.25^{* * *}$ & $0.21^{* * *}$ & $0.18^{* *}$ & $0.15^{* *}$ & $0.14^{*}$ & $0.13^{*}$ \\
\hline 0.03 & -0.05 & -0.06 & 0.02 & -0.02 & -0.04 & 0.05 & -0.05 & -0.02 \\
\hline $0.20^{* * *}$ & $0.15^{*}$ & $0.17^{* * *}$ & $0.17^{* *}$ & 0.10 & $0.18^{* *}$ & $0.15^{*}$ & $0.14^{*}$ & 0.11 \\
\hline$-0.12^{*}$ & -0.08 & -0.09 & -0.09 & -0.06 & -0.09 & -0.09 & -0.06 & -0.05 \\
\hline $0.17^{* * *}$ & $0.16^{* * *}$ & $0.20^{* * *}$ & $0.22^{* * *}$ & $0.21^{* * * *}$ & $0.20^{* * *}$ & 0.09 & 0.10 & $0.17^{* *}$ \\
\hline$-0.13^{*}$ & $-0.12^{*}$ & $-0.12^{*}$ & $-0.20^{* * *}$ & $-0.24^{* * *}$ & $-0.20^{* * *}$ & -0.05 & -0.03 & -0.04 \\
\hline-0.09 & -0.08 & -0.10 & $-0.16^{* *}$ & $-0.18^{* *}$ & $-0.19^{* *}$ & 0.01 & -0.01 & -0.02 \\
\hline$-0.16^{* * *}$ & $-0.14^{*}$ & $-0.15^{*}$ & $-0.18^{* * *}$ & $-0.17^{* *}$ & $-0.19^{* *}$ & $-0.10^{*}$ & $-0.12^{*}$ & $-0.13^{*}$ \\
\hline-0.02 & 0.04 & 0.04 & $-0.11^{*}$ & $-0.19^{* * *}$ & $-0.18^{* *}$ & 0.09 & 0.03 & 0.12 \\
\hline 0.09 & 0.02 & 0.03 & $-0.14^{*}$ & $-0.20^{* * *}$ & $-0.18^{* *}$ & 0.08 & 0.04 & 0.11 \\
\hline
\end{tabular}

${ }^{\#} p=0.06 ;{ }^{*} p<0.05 ; * * p<0.01 ; * * *<0.001$ 